\title{
AC-PDP Sustain Driver using Bidirectional Switches
}

\author{
Feel-soon Kang ${ }^{\dagger}$
}

\begin{abstract}
To minimize the cost and power consumption of PDP TV, a practical sustain circuit topology is presented with an address-and-display-period-separated driving scheme. The proposed sustain driver employs bidirectional switches to reduce the number of components. Operational principles and corresponding features are illustrated and compared with the conventional approach. The valuable contributions of the proposed high-performing sustainer has been proven by computer-aided simulations and experiments by using a prototype equipped with 7.5-inch diagonal panel operated at $200 \mathrm{kHz}$ switching frequency.
\end{abstract}

Keywords: Energy recovery, Plasma display panel, Sustainer

\section{Introduction}

The appearance of light-emitting diode (LED) TV created a new competitive phase among large-size TVs. Most LED TV may be classified as a kind of liquid crystal display (LCD) TV because it just substitutes LED for cold cathode fluorescent lamp (CCFL) in back light unit. LCDs appear to have a better position compared with plasma display panels (PDP) in the large-size TV market. However, the keen competition between these two TVs might persist because of the price merit of PDP TVs.

The major issue of PDP manufacturers has always been on reducing costs while minimizing power losses. A reduction of power consumption requires the enhancement of light-emitting efficiencies and minimizing unnecessary energy wastes in a driving process, but without any direct relation to discharge [1]-[7], [9].

Various sustainers employing energy recovery circuits have been studied, as this can reduce power losses and save costs by minimizing the number of components [3]-[8]. Liu's sustainer using a parallel resonance has been proposed in [3]. The parallel resonance between an external inductor and panel capacitance can recover energy loss caused by the capacitive displacement current of the panel. Soft-switching technique has been applied to reduce more power losses. This technique saves a large amount of energy but it has cost issues. Sometimes, it also results in instability because of inconsistency in the input state; the voltage across the panel is only maintained by the input voltage source. To achieve faster rise-time of the panel voltage, sustainers equipped with voltage boost-up function have been introduced [4], [5]. The boost-up function provides for additional time margins. Therefore, the decreasing brightness problem could be solved without limiting the sustain pulse width and efficiency drop. However, it requires a large number of switching devices, which ren-

$广 \quad$ Corresponding Author: Dept. of Control and Instrumentation Engineering, Hanbat National University, Korea. (feelsoon@ieee.org) Received: June 8, 2010; Accepted: July 22, 2010 ders the material expensive. To mitigate the high-cost problem, a revised sustain driver has been proposed in [6]. This method reduces the number of switching devices, but increased voltage stress of the switches is observed due to boost-up operation. In [7], a sustainer adopting a dual resonance scheme has been introduced. The circuit configuration is very simple, but it needs major adjustments in PDP TV assembly, such as for the reset and address driver.

Several PDP manufacturers have adopted Weber's sustain driver presented in [1] and [2] because of its stability, reliability, and other high performances. This sustainer uses the resonance between external inductors and the intrinsic capacitance of the panel. Two capacitors located at both sides of the plasma panel could store the recovered energy. This sustainer has high-energy recovery efficiency, but circuit configuration for practical applications is somewhat complicated and expensive.

To alleviate the cost problem, a modified sustainer using bidirectional switches is proposed. The main objective of this modification is to save on maintenance cost while ensuring high performance and energy recovery efficiency. The operational principle and its features are illustrated, after which they are compared with Weber's sustainer. Functional data for both sustainers, such as voltage and current stress, switching loss, and energy recovery efficiency, are compared by simulations and experiments using a prototype equipped with 7.5 -inch diagonal panel operated at $200 \mathrm{kHz}$ switching frequency.

\section{Analysis of the Proposed Sustainer vs. Weber's Approach}

A circuit model of the Weber's sustainer is analyzed to aid in evaluating the performance of the proposed sustainer. Ideal sustainers are presented to show the basic operation of each sustainer. With given ideal components, all of the sustainers have $100 \%$ recovery efficiency in terms of charging and discharging capacitive loads. 


\subsection{Weber's Sustain Driver}

Fig. 1(a) shows a schematic of Weber's sustain driver; its key waveforms are given in Fig. 1(b). The sustainer is composed of two external inductors, two capacitors, four diodes, and eight switches. Before $t_{0}$, it is assumed that the voltage across the panel maintains $+V_{S}$ by turning on $S_{x 3}$

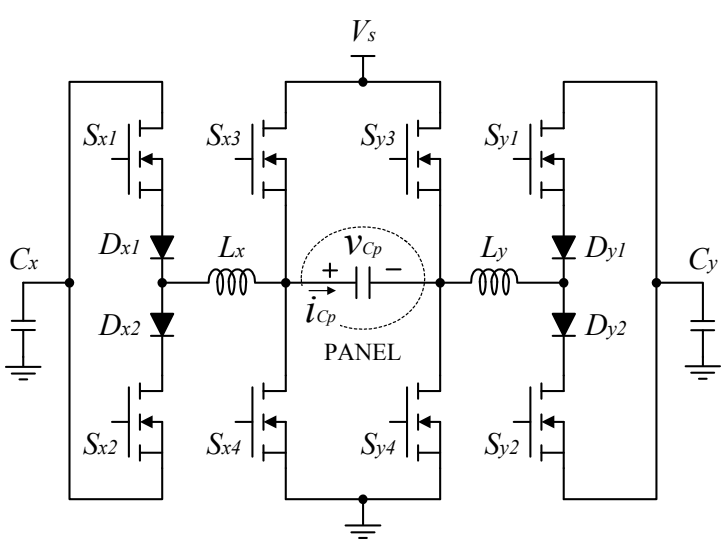

(a)

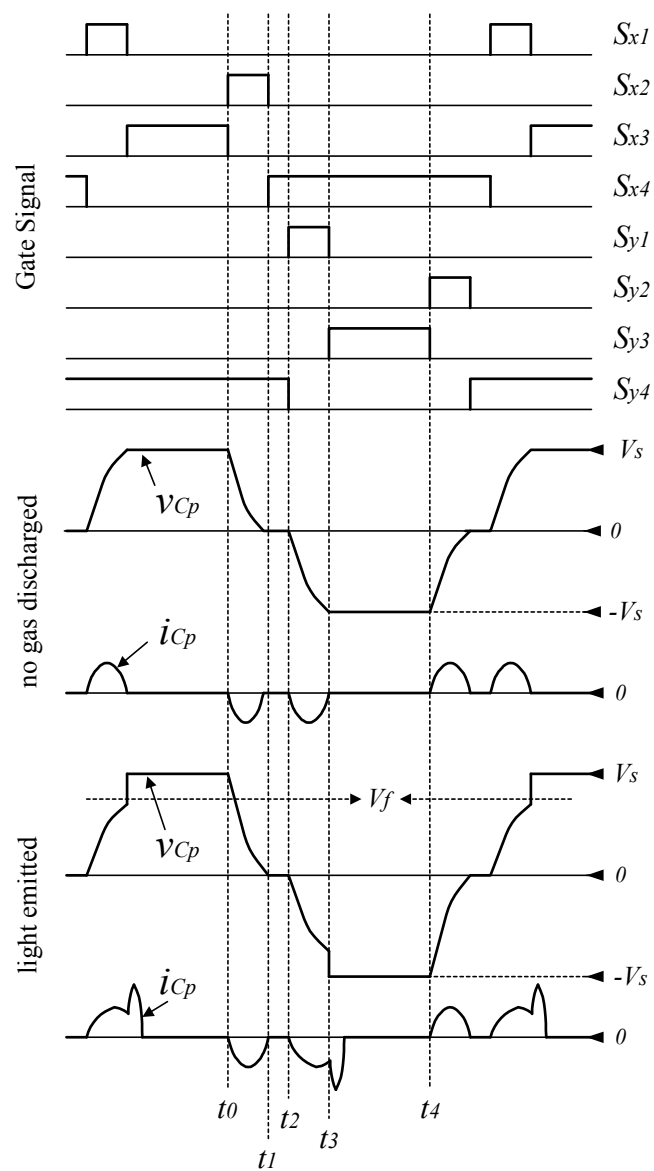

(b)

Fig. 1. Weber's sustain driver: (a) circuit configuration and (b) key waveforms. and $S_{y 4}$. At $t_{0}, S_{x 3}$ is turned off while $S_{x 2}$ is at on-state so that it can recover the energy from the panel. The driver uses the series resonance between the inductor $\left(L_{x}\right)$ and the intrinsic capacitance $\left(C_{P}\right)$ of the panel. The energy is recovered and stored in the capacitor $\left(C_{x}\right)$. When the resonance is completely finished at $t_{1}, S_{x 2}$ is turned off and $S_{x 4}$ is turned on. At $t_{2}, S_{y 4}$ is turned off and $S_{y l}$ is at its on-state so it can supply energy to the panel (e.g., resonance). After complete resonance, the voltage across the panel reaches $V_{S}$; therefore, when $S_{y 3}$ is turned on at $t_{3}$, no current supplied from the source. In this case, only displacement current flows through the panel to increase panel voltage. On the other hand, if voltage across the panel reaches the discharge inception voltage $\left(V_{f}\right)$, the panel starts a discharge by emitting visible light. In this case, following the flowing displacement current, current is discharged (i.e., a consequence of panel discharge). The next mode is repeated during sustain mode [1], [2].

\subsection{Proposed Sustain Driver}

Fig. 2(a) shows a configuration of the proposed sustainer, which is a modified schematic of the aforementioned Weber's circuit. The resonant inductor is connected directly to the external capacitor at both sides. In practice, this circuit configuration is useful to minimize voltage surge occurring at transient periods. Two bidirectional switches $\left(S_{x l}, S_{y l}\right)$ are employed to recover and supply energy to the panel; in the Weber's circuit, four switches are needed for the same function. The proposed sustainer has more advantages compared with the Weber's circuit because of these simple modifications in the circuit configuration. It can save two switches with corresponding gate-amps, resulting in decreased cost and reduced size. The operational modes are explained under the same conditions for the previously mentioned circuit.

Before $t_{0}$, the voltage across the panel is assumed to maintain $+V_{S}$ by turning on $S_{x 3}$ and $S_{y 4}$. $S_{x 3}$ is turned off at $t_{0}$ while $S_{x l}$ is at its on-state so that it can recover the energy from the panel. It uses the series resonance between the inductor $\left(L_{x}\right)$ and the intrinsic capacitance $\left(C_{P}\right)$ of the panel Energy is then recovered and stored in the capacitor $\left(C_{x}\right)$. When resonance is completed at $t_{1}, S_{x l}$ is turned off and $S_{x 4}$ is turned on. At $t_{2}, S_{y 4}$ is turned off and $S_{y l}$ is at its on-state in order to supply energy to the panel (e.g., resonance). After complete resonance, the voltage across the panel reaches $-V_{S}$; therefore, when $S_{y 3}$ is turned on at $t_{3}$, there is no current supplied from the source. In this case, only displacement current flows through the panel to increase panel voltage. On the other hand, if voltage across the panel reaches the discharge inception voltage $\left(V_{f}\right)$, the panel starts discharge while emitting visible light. In this case, a discharging current can be observed (i.e., from panel discharge after the flowing displacement current). The next mode is essentially similar to the aforementioned modes except for voltage polarity. As mentioned earlier, the operational modes are the same, except that the bidirectional switch plays two roles, namely, recovery and supply. 


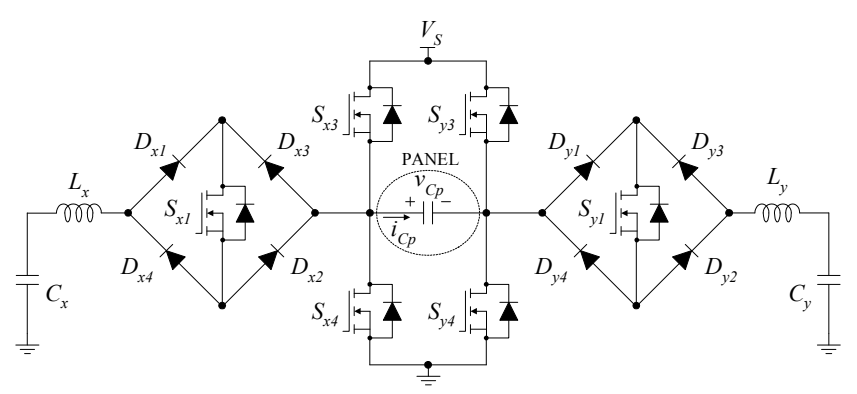

(a)

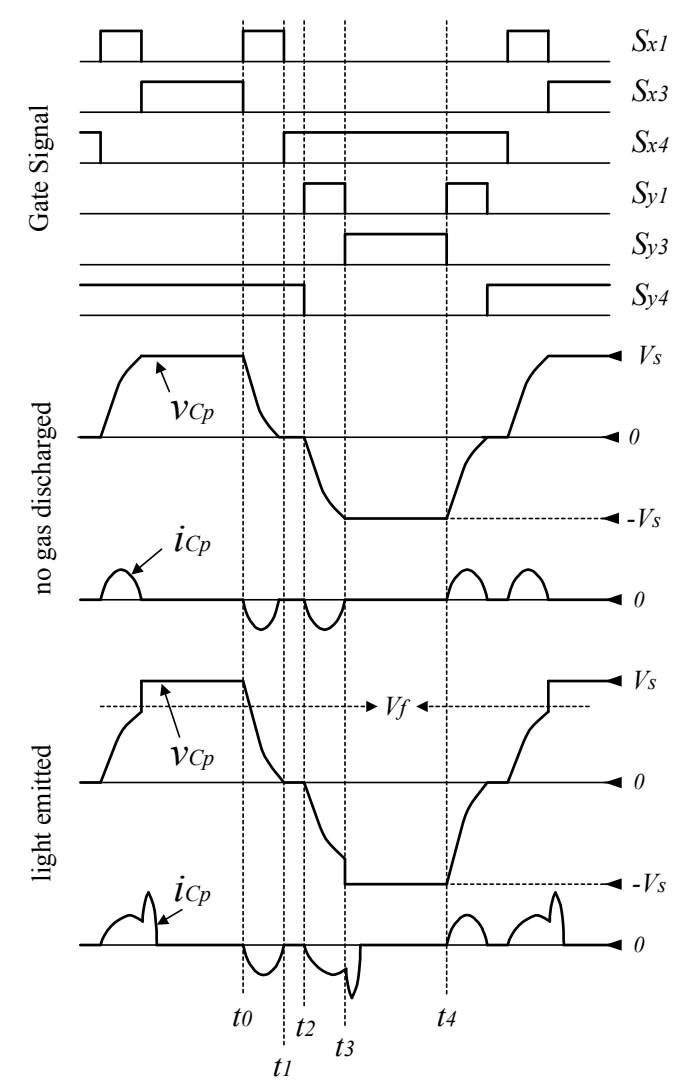

(b)

Fig. 2. Proposed sustainer: (a) circuit configuration and (b) key waveforms.

\subsection{Design Guideline}

The characteristic of the panel determines the operating frequency of the sustain driver. Typically, the panel operates at the range of $80-200 \mathrm{kHz}$. Based on the brightness requirement of PDP, the number of sustain pulses are controlled under a fixed operating frequency. To ensure stable panel discharge, a flat-topped sustain period of $1-1.5 \mu \mathrm{s}$ is required. To calculate the proper value of the inductor and capacitor, as well as to obtain complete resonance, we present a design equation [Eq. (1)]. In the proposed sustainer, interval $t_{1}-t_{0}$ (and $t_{3}-t_{2}$ ) is equal to half the series resonant period given as

$$
t_{1}-t_{0}=t_{3}-t_{2}=\pi \sqrt{L_{x} \cdot C_{p}}=\pi \sqrt{L_{y} \cdot C_{p}}
$$

The inductor value can be obtained easily by Eq. (1) because the panel capacitance is generally obtainable by panel size. In the case of the 7.5-inch diagonal panel with $\mathrm{Xe}=4 \%, \mathrm{Ne}=30 \%$, and 400 Torr, the panel capacitance is about $2.5 \mathrm{nF}$. Obtaining the exact values of each element is difficult because of non-ideal components, such as stray capacitance, inductance, and other unexpected factors. Moreover, panel capacitance $C_{p}$ always changes its capacitance depending on the pixel's on/off conditions. Hence, a trial-and-error method is recommended, conducted through simulations or experiments with the panel conditions, in order to determine more optimal values. The on-resistance of power MOSFET should be considered carefully when selecting switching devices because it hugely influences system efficiency.

\section{Simulation and Experiments}

To assess the performance of the proposed sustainer, Weber's sustainer is tested under the same conditions. To check the basic operation, computer-aided simulations were first implemented. Each of the switching condition is listed in Table 1.

TD denotes time-delay; TR is the rise-time; TF is the fail-time. PW is the pulse width, and PER denotes the switching period of the command signal. PER is set to $5 \mu \mathrm{s}$ so each sustainer is operated at $200 \mathrm{kHz}$. The flat-topped sustain period is set to $1.5 \mu \mathrm{s}$ for producing stable light waveforms. In the case of the proposed sustainer, bidirectional switches $\left(S_{x l}\right.$ and $\left.S_{y l}\right)$ are operated twice to carry out recover and supply roles. The rise-time and fall-time of every switch are $10 \mathrm{~ns}$ and $20 \mathrm{~ns}$, respectively. The components used in the simulation are given in Table 2. Power MOSFETs (500V/20A ratings) are deployed for the switching devices. Equivalent series resistance (ESR) of the inductor and the external capacitor are set to 0.02 and 0.01 $\mathrm{ohm}$, respectively. Considering the worst condition of the panel, the equivalent capacitance is set to $2.5 \mathrm{nF}$ before ignition and to $5 \mathrm{nF}$ during ignition with visible light.

Fig. 3 shows the simulation results of each sustainer at $V_{S}=180 \mathrm{~V}$. The voltage found across the panel and

Table 1. Control signals for simulation

\begin{tabular}{|c|c|c|c|c|c|c|c|}
\hline Sustainer & SW & $\begin{array}{l}\text { TD } \\
{[\mu \mathrm{s}]}\end{array}$ & $\begin{array}{l}\mathrm{PW} \\
{[\mu \mathrm{s}]}\end{array}$ & Sustainer & SW & $\begin{array}{c}\text { TD } \\
{[\mu \mathrm{s}]}\end{array}$ & $\begin{array}{l}\mathrm{PW} \\
{[\mu \mathrm{s}]}\end{array}$ \\
\hline \multirow{8}{*}{ Weber } & Sx 1 & 3.5 & 0.5 & \multirow{8}{*}{ Proposed } & \multirow[t]{2}{*}{$\mathrm{Sx} 1$} & 3.5 & 0.5 \\
\hline & $\mathrm{Sx} 2$ & 0 & 1.0 & & & 0 & 1.0 \\
\hline & $\mathrm{Sx} 3$ & 4.0 & 1.0 & & $\mathrm{Sx} 3$ & 4.0 & 1.0 \\
\hline & $\mathrm{Sx} 4$ & 0.5 & 2.0 & & $\mathrm{Sx} 4$ & 0.5 & 2.0 \\
\hline & Sy1 & 1.0 & 0.5 & & Sy1 & 1.0 & 0.5 \\
\hline & Sy2 & 2.5 & 1.0 & & & 2.5 & 1.0 \\
\hline & Sy3 & 1.5 & 1.0 & & Sy3 & 1.5 & 1.0 \\
\hline & Sy4 & 3.0 & 2.0 & & Sy4 & 3.0 & 2.0 \\
\hline
\end{tabular}


Table 2. Components list for simulation

\begin{tabular}{|c|c|c|c|}
\hline & & Weber & Proposed \\
\hline \multirow{3}{*}{ Switch } & \multirow{2}{*}{ Symbol } & $\mathrm{Sx} 1-\mathrm{Sx} 4$ & $\mathrm{~S} \times 1 / \mathrm{S} \times 3 / \mathrm{S} \times 4$ \\
\hline & & Sy1-Sy4 & Sy1/Sy2/Sy3 \\
\hline & Value & $\begin{array}{c}\mathrm{V}_{\mathrm{DS}}=500 \mathrm{~V} \\
\mathrm{I}_{\mathrm{D}}=20 \mathrm{~A}\end{array}$ & $\begin{array}{c}\mathrm{V}_{\mathrm{DS}}=500 \mathrm{~V} \\
\mathrm{I}_{\mathrm{D}}=20 \mathrm{~A}\end{array}$ \\
\hline \multirow{3}{*}{ Diode } & \multirow{2}{*}{ Symbol } & $\mathrm{Dx} 1, \mathrm{Dx} 2$ & Dx 1-Dx4 \\
\hline & & Dy1,Dy2 & Dy1-Dy4 \\
\hline & Value & $\begin{array}{c}\mathrm{V}_{\mathrm{DS}}=500 \mathrm{~V} \\
\mathrm{I}_{\mathrm{D}}=20 \mathrm{~A}\end{array}$ & $\begin{array}{c}\mathrm{V}_{\mathrm{DS}}=500 \mathrm{~V} \\
\mathrm{I}_{\mathrm{D}}=20 \mathrm{~A}\end{array}$ \\
\hline \multirow{2}{*}{ Inductor } & Symbol & Lx,Ly & Lx,Ly \\
\hline & Value & $10 \mu \mathrm{H}$ & $10 \mu \mathrm{H}$ \\
\hline \multirow{2}{*}{ Capacitor } & Symbol & $\mathrm{Cx}, \mathrm{Cy}$ & $\mathrm{Cx}, \mathrm{Cy}$ \\
\hline & Value & $220 \mathrm{nF}$ & $200 \mathrm{nF}$ \\
\hline \multicolumn{2}{|c|}{ ESR of inductor } & $0.02 \mathrm{ohm}$ & $0.02 \mathrm{ohm}$ \\
\hline \multicolumn{2}{|c|}{ ESR of capacitor } & $0.01 \mathrm{ohm}$ & $0.01 \mathrm{ohm}$ \\
\hline
\end{tabular}

displacement current waveforms before ignition are presented. Fig. 3(a) shows the simulation results of Weber's sustain driver given in Fig. 1(a). It employs eight switches that are opened and closed by eight switching states. This circuit utilizes the natural resonance between the inductor and the intrinsic capacitance of the panel. If the equivalent capacitance of the panel is constant, a complete resonance resulting in high energy recovery efficiency is always guaranteed. If it fails to meet the requirement for complete resonance, recovery efficiency will decrease considerably. Fig. 3(b) shows the voltage across the panel and the current flowing through the panel for the proposed sustainer. Both

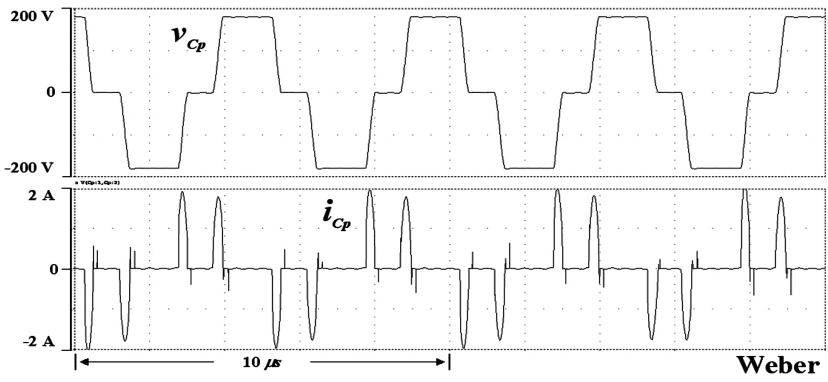

(a)

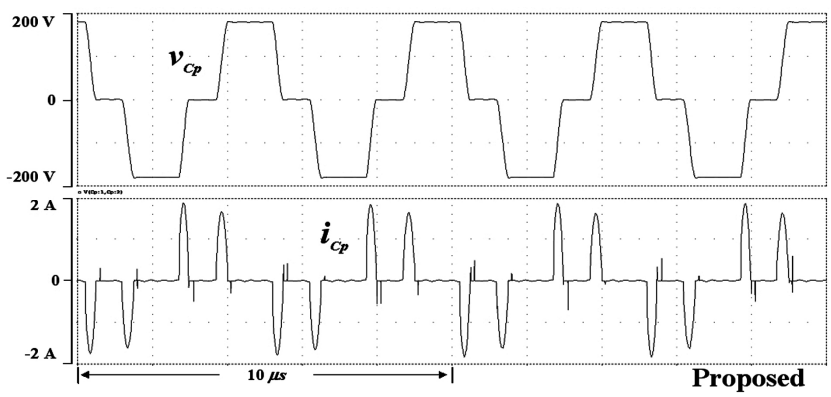

(b)

Fig. 3. Simulation waveforms of voltage across the panel and current flowing through the panel at $\mathrm{Vs}=180 \mathrm{~V}$ : (a) Weber's sustainer and (b) proposed sustainer.

simulation results show almost the same waveforms, mainly because the basic operation is the same for both sustainers; the objective of the proposed sustainer is merely to save the number of switches in order to achieve low cost.

Based on theoretical analysis and simulation results, we tested the proposed sustainer by using a prototype. Fig. 4

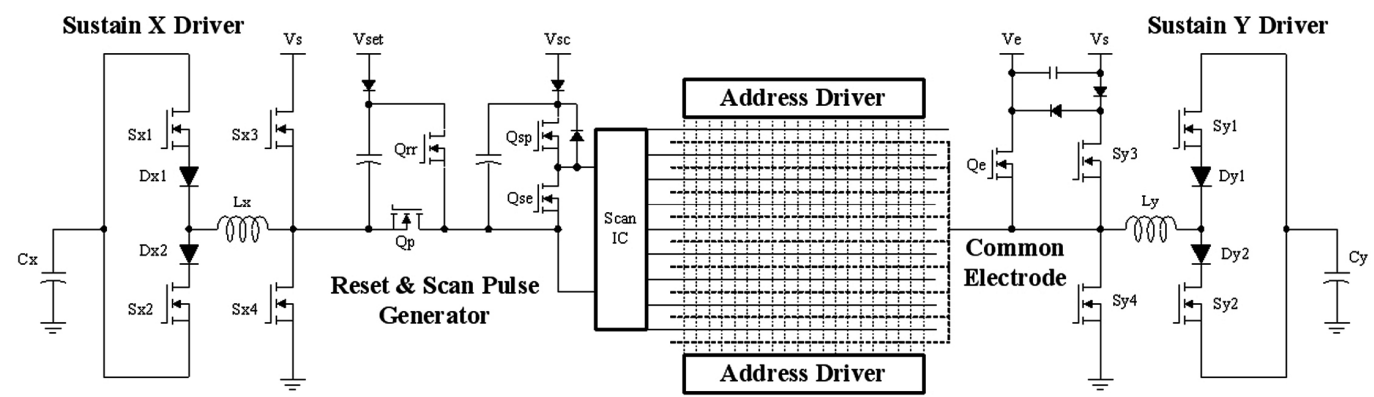

(a)
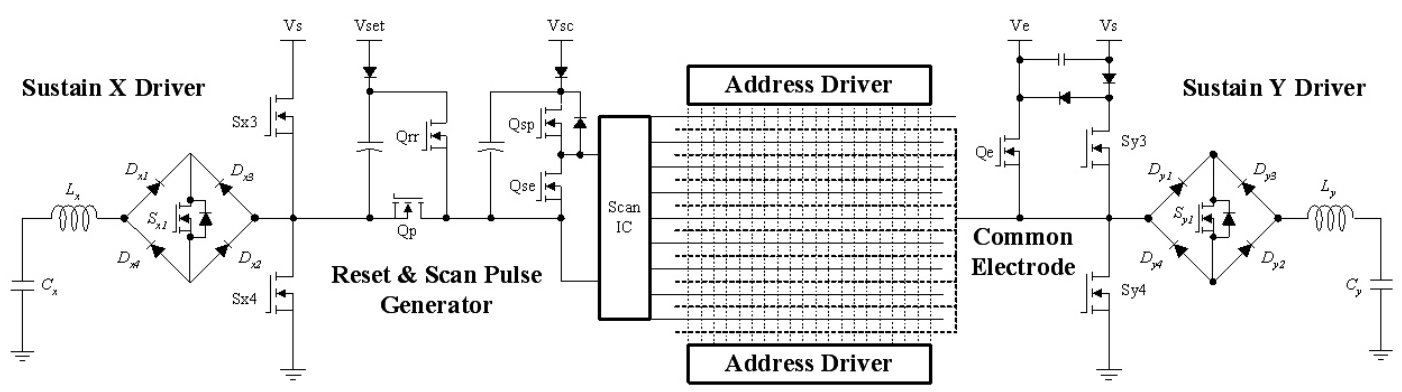

(b)

Fig. 4. Experimental set-up of each sustain driver: (a) Weber's circuit and (b) proposed driver. 
Table 3. Specifications of the prototype

\begin{tabular}{cl}
\hline Items & \multicolumn{1}{c}{ Specifications } \\
\hline Switch & Power MOSFET $\quad \mathrm{V}_{\mathrm{DS}}=500 \mathrm{~V} \quad \mathrm{I}_{\mathrm{D}}=20 \mathrm{~A}$ \\
Diode & Internal diode of the switch \\
Inductor & $10 \mu \mathrm{H} /$ Aircore \\
Capacitor & $220 \mathrm{nF} / \mathrm{Metallized} \mathrm{Polyester} \mathrm{Film}$ \\
& $7.5 \mathrm{inch}$ AC PDP \\
Panel & $\mathrm{He}+\mathrm{Ne}(30 \%)+\mathrm{Xe}(4 \%), 400$ Torr \\
\hline
\end{tabular}

shows the experimental set-up for both AC-PDP drivers. Generally, AC-PDP driver is divided into three parts: a reset circuit, an address driver, and a sustain driver. During the sustain period, the separating switch $\left(Q_{p}\right)$ is always turned on while the other circuits, such as the scan pulse generator and address driver, are disabled. The specifications of the components are listed in Table 3. In the experiment, each control signal is generated by FPGA using a very high speed integrated circuit hardware description language (VHDL).

In ADS driving method, the address and sustain period are separate. In the experiment, any driving voltages added from the address driver that could influence the sustain voltage of the next display period are not included. Address period to ground is maintained. Consequently, the proposed sustainer needs a higher voltage (i.e., over $200 \mathrm{~V}$ ) to ignite the plasma completely. In experiments, sustain pulses are generated during $100 \mu$ s per $500 \mu \mathrm{s}$, as shown in Fig. 5 .

Fig. 6(a) shows the experimental waveforms of the voltage across the panel $\left(v_{C p}\right)$ and the current flowing through the panel $\left(i_{C p}\right)$ at the switching frequency of $200 \mathrm{kHz}$. In this case, PDP does not emit visible light; thus, only displacement current is flowing through the panel, hence changing the polarity of the panel voltage. Fig. 6(b) shows the experimental waveforms when ignited with visible light.

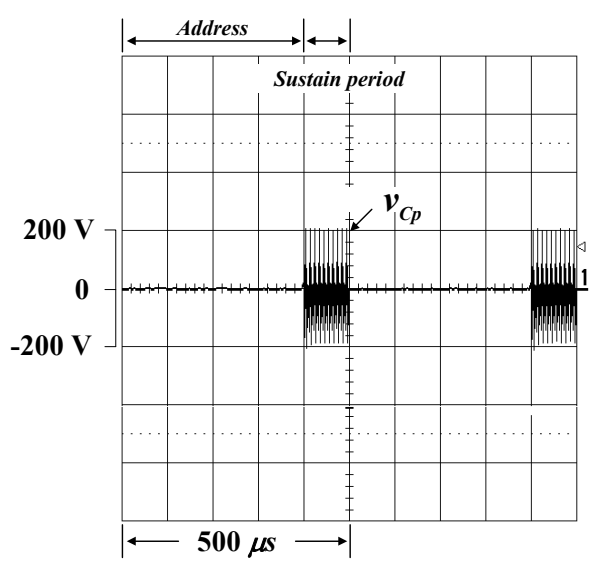

Fig. 5. Address-and-display separated driving method for experiments.

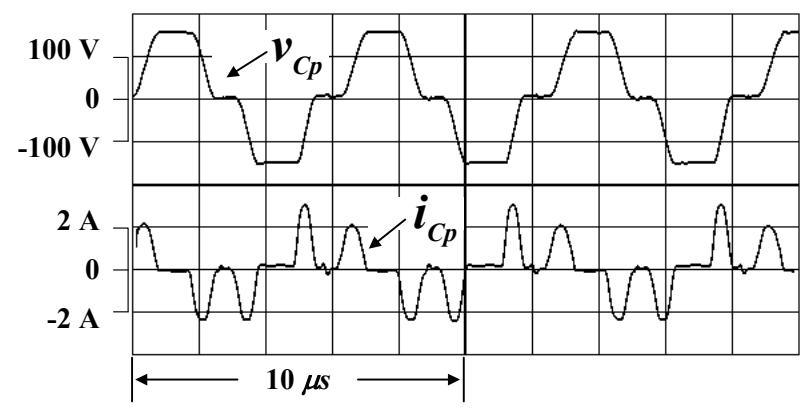

(a)

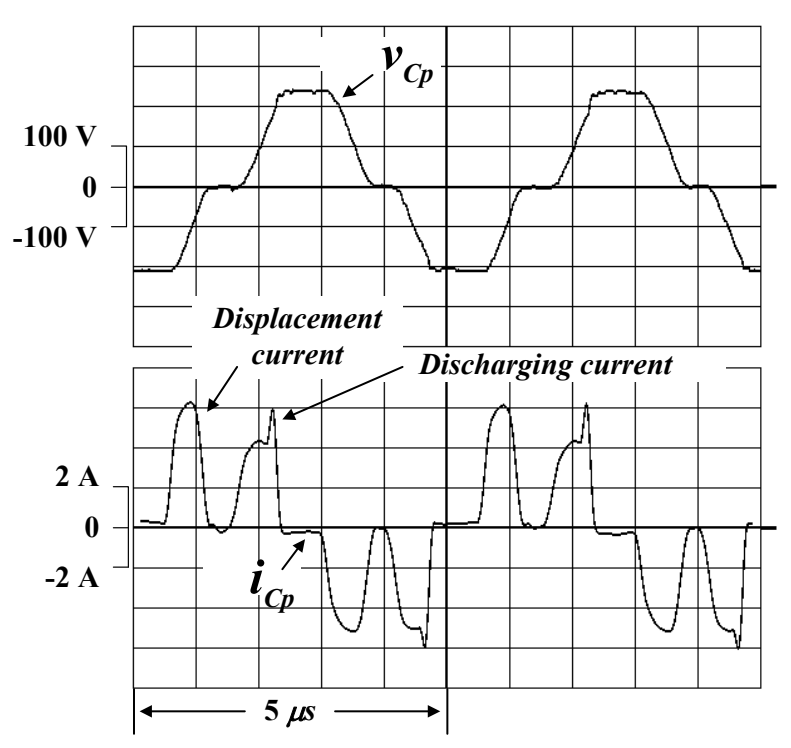

(b)

Fig. 6. Experimental waveform of panel voltage and current: (a) before ignition at $\mathrm{V}_{\mathrm{S}}=180 \mathrm{~V}$ and (b) during ignition with visible light $\left(\mathrm{V}_{\mathrm{S}}=240 \mathrm{~V}\right)$.

Discharging current flows through the panel and appears at the end part of the panel current while following the displacement current. Voltage across the panel is affected slightly by the discharging current.

Fig. 7 shows the comparative results of voltage stress on each sustain driver. Based on the position of the switches, both circuits have different voltage stress. In the case of Weber's sustainer, $S_{x 1}$ and $S_{x 2}$ have little high voltage stress because of the effect of the inductor. On the other hands, $S_{x l}$ of the proposed sustainer has little low voltage stress compared with Weber's circuit. This could have resulted from the positional modification of the inductor connected directly to the external capacitor.

Comparative results for the current stress on each sustain driver are given in Fig. 8. The current stress in both sustainers shows almost equivalent values because the basic operation is the same, while the topological configuration is modified.

Fig. 9 shows the comparative results of the switching losses. Before the ignition, as presented in Fig. 9(a), the switching loss of $S_{x l}$ in the proposed sustainer is slightly 


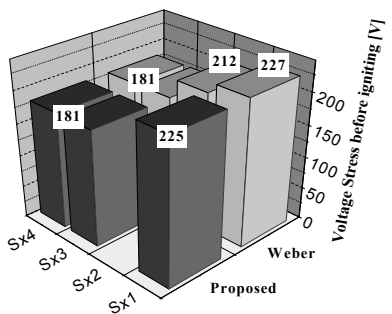

(a)

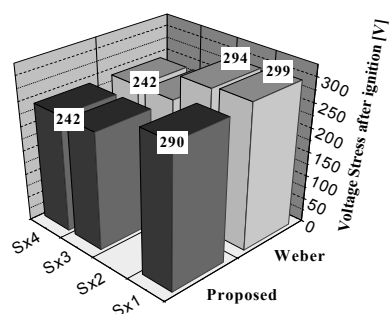

(b)
Fig. 7. Comparison of voltage stress: (a) $V_{S}=180 \mathrm{~V}$ and (b) $\mathrm{V}_{\mathrm{S}}=240 \mathrm{~V}$.

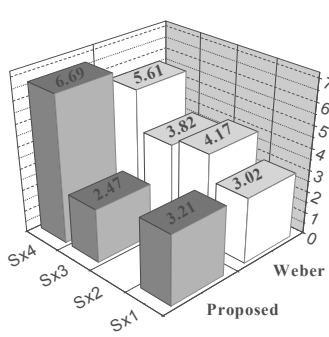

(a)

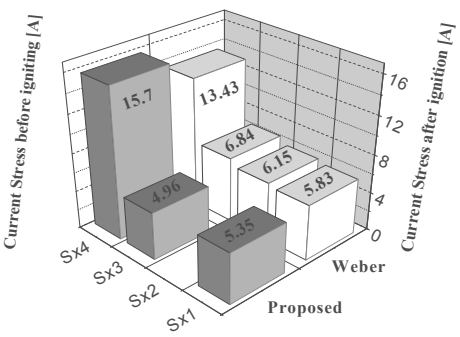

(b)
Fig. 8. Comparison of current stress: (a) $V_{S}=180 \mathrm{~V}$ and (b) $\mathrm{V}_{\mathrm{S}}=240 \mathrm{~V}$.

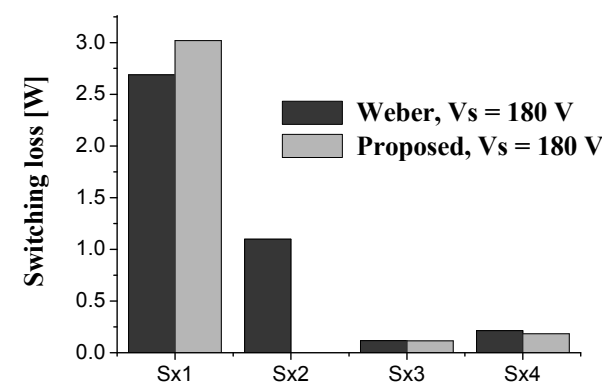

(a)

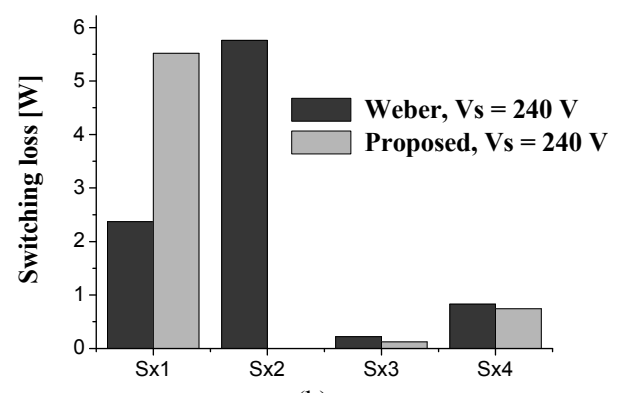

(b)

Fig. 9. Comparison of switching loss: (a) $\mathrm{V}_{\mathrm{S}}=180 \mathrm{~V}$ and (b) $\mathrm{V}_{\mathrm{S}}=240 \mathrm{~V}$.

higher than that of Weber. Switching loss doubles during ignition because the $S_{x I}$ of the proposed sustainer plays two roles: recovery and supply. However, since the proposed sustainer can eliminate $S_{x 2}$, total switching losses becomes similar in both sustainers.

Fig. 10 shows the comparative results of conduction loss on power diodes. Although the proposed sustain driver has two additional diodes in the sustain $\mathrm{X}$ driver, total conduction loss is slightly lower than Weber's approach, given the location of the recovery inductor. It improves to $0.309 \mathrm{~W}$ before ignition and $0.635 \mathrm{~W}$ during a light emitting condition. In the proposed sustainer, the voltage across each diode is measured at an average of $96.3 \mathrm{~V}$ before ignition corresponding to an average of $134.7 \mathrm{~V}$ during ignition. On the other hand, voltage is measured at an average of 203.6 $\mathrm{V}$ and $272.7 \mathrm{~V}$ in the Weber's approach. Voltage across the switching devices becomes lower in the proposed approach because voltage stress is divided by the additional diodes.

Fig. 11 shows the comparative result of power consumption for both sustainers. Power consumption includes switching losses, conduction losses, and other losses. Before ignition, the proposed sustain driver can be reduced to about $1.44 \mathrm{~W}$. During ignition with visible light, the sustainer reduces more power consumption by approximately $5.4 \mathrm{~W}$. The proposed sustainer can reduce conduction loss, which is proportional to the quantity of flowing current, because it has eliminated two switching devices in the main circuit.

Fig. 12 shows the comparison of energy recovery efficiency on each sustainer. Before ignition, Weber's sustainer shows on average $82.38 \%$ of energy recovery efficiency increased by $85.69 \%$ after ignition. The proposed sustainer shows on average $92.37 \%$ before ignition and is decreased

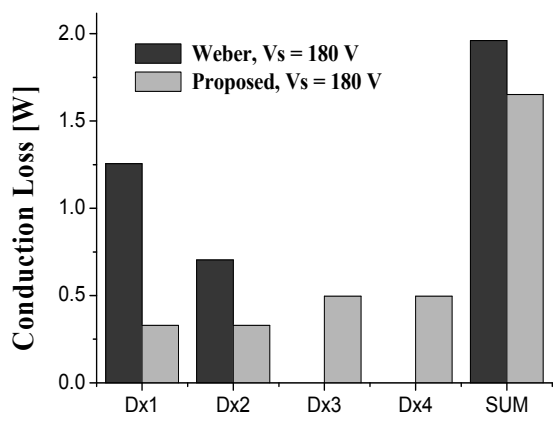

(a)

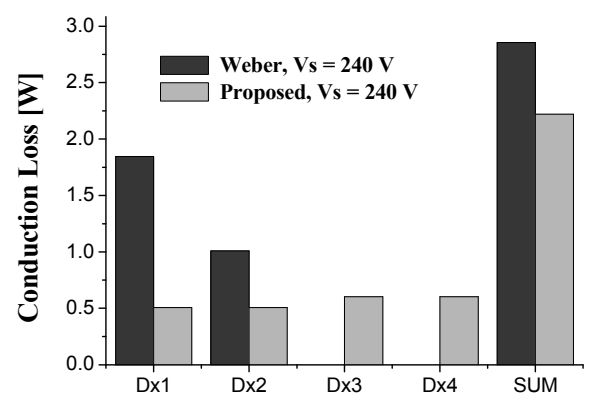

(b)

Fig. 10. Comparison of conduction loss, (a) $\mathrm{V}_{\mathrm{S}}=180 \mathrm{~V}$, (b) $\mathrm{V}_{\mathrm{S}}=240 \mathrm{~V}$. 


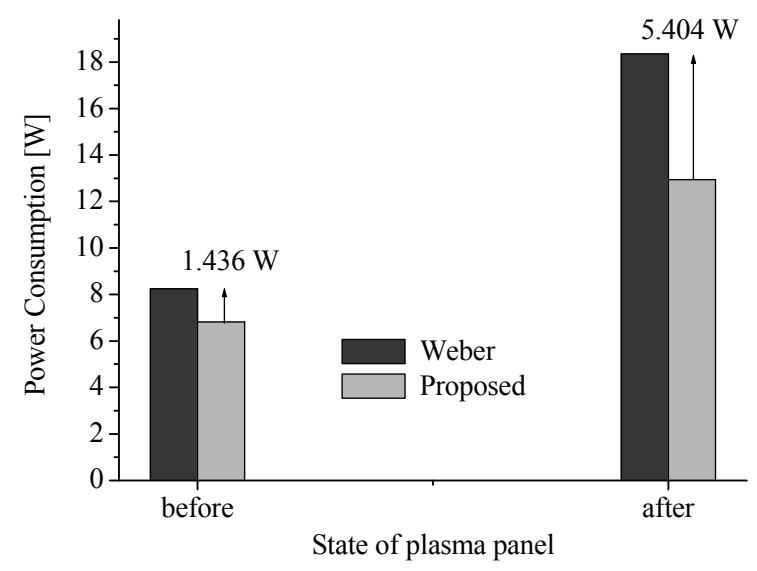

Fig. 11. Comparison of power consumption: (a) before ignition and (b) after ignition.

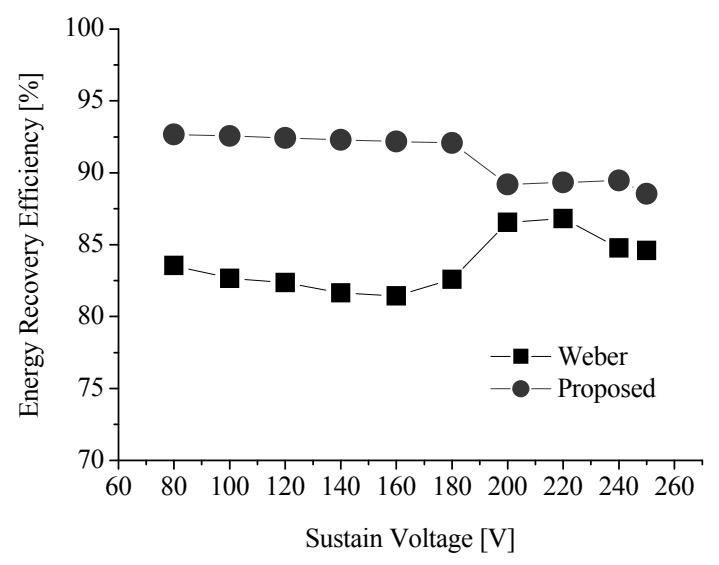

Fig. 12. Comparison of energy recovery efficiency according to sustain voltages.

to $89.14 \%$ during light emission. Results show that the proposed sustainer has improved energy recovery efficiency by about $10 \%$ before ignition, $3.45 \%$ during igniting state, and $6.72 \%$ on the average compared with the Weber's sustainer. Results also suggest that the proposed sustainer can increase energy recovery efficiency regardless of panel conditions (i.e., whether it is igniting or not).

The recovery efficiency is not the same as conventional power efficiency, which is defined by the power delivered to a load. In PDP operations, power is not delivered to the panel; it is simply charged and then discharged. Therefore, the efficiency at which the sustain driver recovers energy is defined as recovery efficiency and expressed by the input current obtained from the power supply [5]-[7],[15],[16].

\section{Conclusion}

A modified sustainer is proposed to reduce the cost and power consumption of PDP TV. Basic operation is equal to that of Weber's sustainer, except for the bidirectional switches and the location of the external inductor. To verify the proposed high-performing sustain driver, the previously available Weber's circuit has been analyzed; both are then compared by computer-aided simulations and experiments using a prototype. The valuable achievements of the proposed sustain driver can summarized as:

(1) Cost savings by employing bidirectional switches;

(2) Alleviated voltage surge by changing inductor position;

(3) Decreased power consumption with reduction in conduction loss; and

(4) Improvements in energy recovery efficiency by about $6.7 \%$ compared with the conventional Weber's sustainer.

\section{References}

[1] L. F. Weber and M. B. Wood, "Energy recovery sustain circuit for the AC plasma displays," in Proc. of SID'87 Dig., 1987, pp. 92-95.

[2] L. F. Weber and K. W. Warren, "Power efficient sustain driver and address drivers for plasma panel," US patent 4886 349, Sept., 1989.

[3] C. C. Liu, C. L. Chen, and K. M. Lee, "A Novel Energy-Recovery Sustaining Driver for Plasma Display Panel," IEEE Trans. Ind. Electron., Vol. 47, No. 6, pp. 1271-1277, Dec., 2000.

[4] C. U. Kim, F. S. Kang, J. H. Cho, and W. S. Yoon, "An efficient AC-PDP sustain driver employing boost-up function," in Proc. of IEEE IECON'02, Nov. 5-8, 2002, Sevilla, Spain, pp. 135-139.

[5] F. S. Kang, S. J. Park, J. H. Cho, W. S. Yoon, C. U. Kim, "High-Performance Sustain Driver for Plasma Display," IEEE Trans. Ind. Electron., Vol. 53, No. 4, pp. 1322-1327, Aug., 2006.

[6] F. S. Kang, and S. G. Oh, "An Efficiently Revised Sustain Driver for AC Plasma Display," IEEE Trans. Consumer Electron., Vol. 50, No. 1, pp. 8-14, Feb., 2004.

[7] F. S. Kang, S. J. park, C. U. Kim, “A Novel AC-PDP Sustain Driver Based on Dual Resonance in Sustaining Mode Operation," IEEE Trans. Ind. Electron., Vol. 50, No. 3, pp. 536-544, June, 2003.

[8] H. B. Hsu, C. L. Chen; S. Y. Lin; and K. M. Lee, "Regenerative Power Electronics Driver for Plasma Display Panel in Sustain-Mode Operation," IEEE Trans. Ind Electron., Vol. 47, No. 5, pp. 1118-1125, Oct., 2000.

[9] A. Sobel, "Plasma Displays," IEEE Trans. Plasma Science, Vol. 19, No. 6, pp. 1032-1047, Dec., 1991.

[10] John G. Webster et al., The Measurement, Instrumentation, and Sensors Handbook, CRC \& IEEE Press, 1999, Vol. 2, pp. 93/1-30.

[11] J. Ryeom et al., "A Drive-Voltage Reduction of AC PDPs by Use of Space-Charge-Control Pulses," Conf. Record of the International Display Research, 1997, 
pp. 390-393.

[12] F. S. Kang, "Series Resonant Sustain Driver and Reset Circuit Composition Using a Single Voltage Source for an Efficient Plasma Display," Displays, Vol. 25, No. 4, pp. 123-134, Nov., 2004.

[13] J. Y. Lee, J. S. Kim, N. S. Jung, and B. H. Cho, “The Current Injection Method for AC Plasma Display Panel (PDP) Sustainer," IEEE Trans. Ind. Electron., Vol. 51, No. 3, pp. 615-622, June, 2004.

[14] S. K. Han, G. W. Moon, M. J. Youn, "A Novel Current-Fed Energy-Recovery Sustaining Driver for Plasma Display Panel (PDP)," IEEE Trans. Ind. Electron., Vol. 52, No. 6, pp. 1702-1704, Dec., 2005.

[15] F. S. Kang, "Series Resonant Sustain Driver for AC Plasma Display," IEEE Trans. Consumer Electron., Vol. 54, No. 3, pp. 1415-1421, Aug., 2008.

[16] F. S. Kang, Y. H. Kwon, and W. K. Choi, "Capacitor Clamped Sustainer for AC Plasma Display," IEEE Trans. Consumer Electron., Vol. 55, No. 4, pp. 23012307, Nov., 2009.

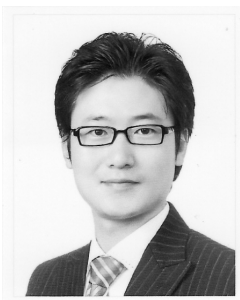

Feel-soon Kang received M.S. and Ph.D. degrees from Pusan National University, Busan, Korea in 2000 and 2003, respectively. From 2003 to 2004, he was with the Department of Electrical Engineering, Osaka University, Osaka, Japan as a Post-doctoral Fellow. Since 2004, he has been with the Department of Control and Instrumentation Engineering, Hanbat National University, Daejeon, Korea as an assistant professor. His research activities are in the area of power electronics including design and control of power converters for display applications, and multilevel inverters for photovoltaic power generating systems. He received an Award from IEEE Industrial Electronics Society and the Best Presentation Prize at IEEE IECON'01 be held in Denver, Colorado USA in 2001. He was honored an Academic Award from Graduate School of Pusan National University and Habat National University in 2003 and 2005, respectively. And he also received several Best Paper Awards from The Korean Institute of Power Electronics (KIPE), and The Korea Institute of Maritime Information and Communication Science (KIMICS). Dr. Kang is an Associate Editor in the IEEE Transactions on Industrial Electronics. 